\title{
Analysis of the implementation of the International Safety Management Code using motivation theory: the seafarer's views
}

\author{
Tem Suzie-Solange Mbong, Despena Andrioti Byguraa
}

Centre for Maritime Health and Society, Institute of Public Health, University of Southern Denmark, Esbjerg, Denmark

\begin{abstract}
Background: "Safety First!" as it is always said, safety is a primary concern in any human activity. Shipping, one of the most dangerous industries in the world demands the establishment and implementation of safety rules, regulations and standards. Before the International Safety Management (ISM) Code was adopted and came into effect, the maritime industry experienced catastrophic disasters which resulted in loss of life and property. The occurrence of huge marine casualties triggered maritime safety rules, regulations and standards at an international level. International maritime safety standards are meant to create uniformity in safety rules and regulations. Human errors are considered the most important reason for maritime accidents. The ISM Code has been established to clarify the responsibilities of safety on vessels and to mitigate the occurrence of human errors by creating a safety-oriented organizational culture. There is still a question of whether this culture is actively practised by shipping companies. Through the lens of Kanter's theory of structural empowerment and Alderfer's theory of employee motivation, this study sought to explore seafarers' views and perceptions of the implementation of the ISM Code.

Materials and methods: In-depth interviews were conducted with 6 participants (4 seafarers and 2 resource maritime industry persons). The interviews with seafarers took place on the $22^{\text {nd }}$ of October, 2019. A semi-structured questionnaire was used to describe the views of the participants in relation to the implementation of the ISM Code on their ship in the following areas: communication, organizational commitment, management involvement, reporting system, and empowerment of employees

Results and Conclusions: The participants pointed out that with the implementation of ISM Code the maritime personnel's safety attitudes have improved. The employees enthusiastically participate in safety meetings and trainings. The organization on board is more open, so is the communication between officers and the crew. Working on board is nowadays teamwork instead of being autocratic.
\end{abstract}

(Int Marit Health 2021; 72, 3: 172-178)

Key words: International Safety Management (ISM) Code, seafarers, maritime industry (shipping), structural empowerment, employee motivation

\section{INTRODUCTION}

The International Safety Management (ISM) Code became mandatory in 1998 as a response to poor management practices and major shipping accidents [1]. The Code establishes safety-management objectives and requires a safety management system (SMS) to be established by "the company", which is defined as the shipowner or any person, such as the manager, who has assumed responsibility for operating the ship. The purpose of the ISM Code is to provide an international standard for the safety operation of ships and prevent pollution. The ISM Code is a global regulatory framework with the aim to upgrade the safety and quality levels in the shipping industry.

Dr. Despena Andrioti Bygvraa, University of Southern Denmark, Neils Bohrs Vej 9, 10, +45 Esbjerg, Denmark, e-mail: dab@health.sdu.dk

This article is available in open access under Creative Common Attribution-Non-Commercial-No Derivatives 4.0 International (CC BY-NC-ND 4.0) license, allowing to download articles and share them with others as long as they credit the authors and the publisher, but without permission to change them in any way or use them commercially. 
For decades, the International Maritime Organization (IMO) has had the responsibility to develop uniform measures and designs to improve the safety of international shipping and to prevent marine pollution from ships [2]. Several accidents at sea accelerated the IMO's decision to adopt international guidelines to ensure safety, to prevent human injury or loss of life and to avoid damage to the environment and to property.

Safety is at the core of going to sea. Safety in shipping involves; vessels fit for their purpose, safety of all aboard a ship, safety of seafarers on flagged vessels, environmental safety of coastal waters, to name a few. With this at the forefront, the shipping industry implemented SMS to ensure that commercial vessels are maintained and operate safely to prevent maritime accidents and protect the marine environment. A couple of accidents triggered the shipping industry to take another look into its safety systems.

The Belgian, Roll on/Roll off Passenger and Freight Ferry "The Herald of Free Enterprise" capsized on the $6^{\text {th }}$ of March 10987 in Zeebrugge. 150 passengers out of the 459 who had originally boarded and 38 crew members out of the 80 were killed. A formal investigation ordered by the Flag State (United Kingdom) of the vessel, was chaired by Hon. Mr. Justice Sheen. In his report, released in September 1987, Justice Sheen famously wrote, about the management of the vessel: “(...) All concerned in management, from the members of the Board of Directors down to the junior superintendents, were guilty of fault in that all must be regarded as sharing responsibility for the failure of management. From top to bottom the body corporate was infected with the disease of sloppiness" (Sheen, 1987).

The ferry left the harbour with the bow doors open and as the ferry sped off, the bow wave grew and reached the freeboard. Water got into the car deck and within a few minutes, the ferry capsized. The accident occurred due to omissions and negligence at all levels of the shipping organization preceding the accident. There were no explicit instructions for safety actions leading to unclear roles and responsibilities. This is an important role of senior management, but they were nonchalant towards upgrading safety of the ship [3].

The accident investigation committee concluded that, both ship and crew were not seaworthy. The shipping company took a risk with safety by hastily deploying the ship on a new route [4].

The IMO responded to this maritime accident and others, by developing guidelines (adopted in 1989, IMO Assembly by resolution A.647(16)), concerning shipboard and shore-based management to ensure the safe operation of ships. After some experience in the use of the guidelines, in 1993 IMO adopted the ISM Code for the safe operation of ships and for pollution prevention (the ISM Code) [1] resolution A.741(18). The current 1993 resolution adopted was made mandatory and into force the $1^{\text {st }}$ July 1998.

\section{MATERIALS AND METHODS THE MARITIME COMPANY}

The maritime industry fulfils a critical role in the world economy as the primary carrier of international trade and driver of global supply chains. Commercial shipping transports over $90 \%$ of the world trade in volume, and generates significant revenue for States. Regulating the maritime industry is a challenging task. Due to the nature of the business, ships sail in high seas remote from their managers and regulatory authorities. The ISM Code was introduced into the maritime industry to provide the basis on which ship owners are required to set up written policies and procedures and document safety management systems for implementation in their organizations [5]. A well-established SMS should incorporate the following elements:

- safety and environmental policies;

- procedures to ensure safe operation of ships and protection of the environment;

- defined level of authority and lines of communication;

- procedures for reporting accidents and non-conformities;

- procedures to prepare for and respond to emergency situations;

- procedures for internal audit and management reviews.

\section{THE SEAFARER}

A seafarer is any person who is employed and works in any capacity on a ship covered by the Maritime Labour Convention (MLC). The MLC, also known as the Seafarers' Bill of Rights, protects seafarers' rights by creating a comprehensive set of basic maritime labour principles and rights. As already mentioned, $90 \%$ of world trade is carried by ships. Seafarers, therefore, ensure that the goods and commodities on the ships reach their various destinations. Seafaring has long been identified as a hazardous job with unique pressures and risks $[6,7]$. It is well recognised that shipping safety continues to be a major topic of interest in the maritime community. Findings indicate that the critical factors of ISM Code implementation can be categorised in the crew-related and the company-related dimensions. Also, the fulfilment of the intended purpose of the ISM Code consists of the factors of safety management system efficiency and increased safety, which were also found to be significantly associated with the crew-related dimension of ISM Code implementation [8].

\section{MOTIVATION THEORY}

Determining and understanding the factors that motivate employees is an essential need, since the performance of any organization depends on the availability of a satisfied and motivated workforce. 


\section{Clayton Alderfer's Motivation Management theory (ERG theory)}

Maslow (1970) [9] proposed the hierarchy of human needs in five levels of basic needs as, physiological needs, safety needs, needs for love, affection and belonging, needs for esteem, and needs for self-actualisation. Alderfer [10] expanded Maslow's basic needs and refined them into existence needs, relatedness needs, and growth needs. Alderfer proposed the ERG (Existence, Relatedness, Growth) theory based on results of empirical studies to explain the relationship between satisfaction of needs and human desires.

Existence needs. Existence needs include various forms of safety, physiological and material needs. Physiological needs refer to an individual's pursuit of satisfaction at the vitality level, such as leisure, exercise, food, shelter, clothing, rest, air, water, sleep etc. Safety needs on the other hand, are the needs connected with the psychological fear of loss of job, property, natural calamities or hazards. A seafarer wants protection from such types of fear. Employees prefer adequate safety or security in this regard i.e., protection from physical danger, security of job, pension for old age, insurance cover for life and so on. Employees, who are sufficiently motivated to perform, will be more engaged, productive and committed to their work.

Relatedness needs. Relatedness corresponds to social needs, the need for meaningful interpersonal relations in the work settings with superiors, peers, and subordinates. Managers should develop the ability to listen. For example, through positive communication, a ship captain can establish himself as approachable, open to new ideas and respectful to other's opinions. This will create an active environment with co-workers and seafarers who listen to ideas and concerns of one another making implementation of new procedures easy and a focused motivated team.

Growth needs. These needs are about continuous personal development in one's job, career or profession. Training and development policies are important for demonstrating company's interest in employees' growth. This is a motivational tool because employees see themselves as being prepared for taking on more responsible positions. The company therefore benefits from providing training and enhancing existing workplace skills leading to higher productivity.

\section{EMPOWERMENT THEORY}

Empowerment is "a principal component of managerial and organizational effectiveness... [and] empowerment techniques play a crucial role in a group's development and maintenance" [11]. Employee empowerment, therefore, has been identified as an effective practice necessary to the effective functioning of any organization through the wise usage of human resources [12]. As more organizations are looking for employees who are resourceful and respond creatively to the challenges of the job, empowerment becomes important at both individual and organizational levels.

\section{Kanter's theory of structural empowerment}

Kanter [13] proposes that a leader's effectiveness on the job is influenced by the structural aspects of a work environment that provides access to formal and informal power. A structurally empowered work environment offers access to information, support, resources, and opportunity to all employees [12]. Empowerment is promoted in work environments that provide employees with access to information, resources, support, and the opportunity to learn and develop [14]. Another study states that employees who are empowered become more committed to the organization, fulfil demands effectively, and are more accountable for their work [15].

\section{EMPOWERING THE SEAFARER}

Organizations that empower their employees are those which provide access to information (decisions, data, technology), support (feedback, guidance), resources (money, supplies, time) and opportunities (mobility, growth, participation in committees) to get the work done [14].

The ISM Code implementation offers an opportunity for the shipping industry to move away from a culture biased towards blame, to one of shared sense of personal responsibility for safety throughout the organization. The Code states that it is the responsibility of 'the Company' to take over all duties imposed by the Code and incorporate SMS into normal business operations. This involves assigning the designated person(s) (DPs), who will be a link between ship and shore and clarify levels of authority and lines of communication. The ISM Code has empowered the seafarers in the following ways:

- Organizational commitment. The shipping company as required by the ISM Code has encouraged safe practices in ship operations for a safe working environment for their employees. The shipping company's SMS assesses all risks on their ships, personnel and the environment and establishes necessary safeguards. Moreover, there should be a policy in place for continuous safety improvement skills of personnel, including preparing for emergencies related to both safety and environmental protection. Employees feel empowered to work in an environment where their safety needs are met, and where they are armed with the necessary training to tackle any future incident or accident.

- Management involvement. One of the requirements of the ISM Code for employee empowerment is that the Company gives the necessary support, so the master's duties are performed safely. The Company ensures the 
master has the appropriate training, conversant with the Company's SMS and qualified for this role. Management involvement in seafarers' duties enables them to identify the training needs of individual seafarer. The means of identifying theses needs could be through appraisal reports, records of previous training and performance during drills and exercises. Through these involvements, the Company ensures each ship is manned only by qualified, certified and medically fit seafarers according to international requirements.

- Communication. Another requirement of the ISM Code for the shipping industry is to define lines of communication between shore and shipboard personnel. The SMS operation on board the ship contains clear statements emphasising the master's authority. The master's defined responsibility is to issue appropriate and clear instructions to the understanding of the crew. This enables all personnel involved in the Company's SMS to have adequate understanding of codes and guidelines. Also, seafarers receive relevant information on SMS in a working language(s) understood by them so they can effectively communicate when executing their duties.

- Employee empowerment. The ISM Code requires the shipping industry to define levels of authority among shore and shipboard personnel. The company has defined and documented the responsibility, authority and interrelation of all personnel who manage, perform and verify work relating to and affecting safety and pollution prevention. Moveover, the company provides resources and support for DPs to adequately perform their duties. Acting as a link between the company and those on board; his/her responsibility is monitoring the safety and pollution, prevention aspects of the operation of the ship and ensuring that adequate resources and shore-based support are applied as required. The Company has established measures to respond to hazards, emergencies and accidents, whenever they arise. Other emergency response plans are; drills and exercises, carried out by both on board and offshore personnel whose responsibilities are related to safety and pollution.

- Reporting system. The SMS of the shipping companies include procedures that ensure accidents and hazardous situations are reported to the Company. Investigations to the hazards are carried out followed by an analysis with the objective to improve safety and pollution prevention. Measures are taken to prevent reoccurrence.

\section{METHODS}

A sample of convenience was interviewed in the port of Esbjerg, Denmark. The first researcher visited the local seaman's home at Esbjerg port. Together with the centre facilitator, the first researcher approached the seafarers at the port and they gave their consents for the interview by signing consent forms. The interviews lasted at most 15 minutes, and incentives (telephone cards) were given to those who wanted them.

The participants have been actively working in the maritime industry for the last 6 years. All respondents had the basic safety management training course and had come in contact one way or another, with the ISM Code implementation. In total 6 people $(4$ seafarers and 2 maritime industry resource persons) participated in this study. Two of the seafarers served as officers, while the other two were non-officers. Five of the participants were from Denmark and one from Spain.

To explore the companies' views, a request for participation went out to the Chief Executive Officers via the University of Southern Denmark institutional email address, delineating the purpose of the study with 3 follow-up emails. Two resource persons agreed to participate.

A qualitative, semi-structured individual interview with the respondents encouraged them to express themselves freely. An interview guide was used to keep the respondents focused and give room for their opinions and experiences [16]. The questionnaire consisted of questions gathering background from both employer and employees, and analysing the main research themes; employee empowerment, communication, reporting system, management involvement, motivation and their perception of the ISM Code.

Each respondent was asked similar questions to find out possible irregularities in their answers. For example, the Chief Executive Officers were asked how often they communicate with the ships, how they communicate and if the employees talk about their risks and working conditions. The seafarers on the other hand were asked if how they communicate with their managers/senior officers, if they could freely express their concerns and if they had any concerns at the time of the interview. To evaluate empowerment, the respondents were asked if the DPs are aware of the ship's safety requirements and if there were enough resources and skills to fulfil their duties.

\section{RESULTS}

Using semi-structured one-on-one interviews with seafarers, and phone interviews with resource persons, this study sought to describe the seafarers and resource persons' views on the implementation of the ISM Code and its impact on their work-life (Table 1).

\section{COMMUNICATION}

All the participants stressed that they take part in safety meetings and they have a good knowledge of the ISM Code and safety methods. The resource persons confirmed that 
Table 1. Themes and sub themes of the interviews

\begin{tabular}{|c|c|c|}
\hline $\begin{array}{l}\text { Number } \\
\text { of themes }\end{array}$ & Themes & Sub themes \\
\hline 1 & $\begin{array}{l}\text { Communica- } \\
\text { tion }\end{array}$ & $\begin{array}{l}\text { Relationship with superior and } \\
\text { other crew men } \\
\text { Trust } \\
\text { Empathy }\end{array}$ \\
\hline 2 & $\begin{array}{l}\text { Organizatio- } \\
\text { nal commit- } \\
\text { ment }\end{array}$ & $\begin{array}{l}\text { Educational and training } \\
\text { opportunity }\end{array}$ \\
\hline 3 & $\begin{array}{l}\text { Management } \\
\text { involvement }\end{array}$ & Leader as source of information \\
\hline 4 & $\begin{array}{l}\text { Reporting } \\
\text { system }\end{array}$ & $\begin{array}{l}\text { Lack of communication } \\
\text { Blame or no blame culture }\end{array}$ \\
\hline 5 & $\begin{array}{l}\text { Perception } \\
\text { of the ISM } \\
\text { Code }\end{array}$ & $\begin{array}{l}\text { Helpful } \\
\text { Not helpful }\end{array}$ \\
\hline 6 & $\begin{array}{l}\text { Employee } \\
\text { empower- } \\
\text { ment }\end{array}$ & $\begin{array}{l}\text { Shared governance } \\
\text { Autonomy } \\
\text { Accountability }\end{array}$ \\
\hline
\end{tabular}

ISM - International Safety Management

the personnel are not afraid to stand up and talk about safety issues. All the participants agreed that today, the discussion with all parties is straight forward and has a great influence on how good the ship's spirit and atmosphere are which in turn have a direct effect on the personnel's safety behaviour.

\section{ORGANIZATIONAL COMMITMENT}

When asked how the management supports the personnel in safety issues, the resource persons remarked that, one of the most significant effects of the ISM Code has been that the company and its management have been assigned responsibilities for ensuring safety. Also, they must be able to present an image of safety to the customers who are aware and have higher requirements on safety procedures.

Management attitude towards safety is constantly improving accordingly. The employees also highlighted that the attitude towards safety management in their company management are positive and they support the application of the system.

\section{MANAGEMENT INVOLVEMENT}

All respondents emphasised the involvement of management especially in providing resources for their safety. Most responded positively to their monthly safety meeting held on board their ships with superior, on safety issues. Some respondents agreed that the management provided them with resources including accurate information and guidelines to carry out safety practices.

\section{REPORTING SYSTEM}

When asked how the incidents have been reported and analysed in their shipping companies, they pointed out the existence of a reporting system and thanks to a friendly environment in their ships, they are free to report any near miss or accident anytime it occurs.

\section{PERCEPTION OF THE ISM CODE}

All participants appreciated the implementation of the ISM Code. Some were happy the code is in place to always remind them of safety. Others appreciated the existence of the code because they now pay attention to safety practices and this has improved their safety behaviour whereas before, they just wanted their jobs done as soon as possible.

\section{EMPLOYEE EMPOWERMENT}

When asked about empowerment, they all agreed that training was an important component to understand and perform their specific tasks. So, the felt empowered and continue taking other courses to stay current.

\section{DISCUSSION}

This paper sought to describe seafarers and Chief Executive Officers perceptions on the effectiveness of the ISM Code. Findings showed that the ISM Code has been implemented effectively in the shipping companies, where the interviewees were employed as they haven't experienced any accidents. The effectiveness in the ISM Code implementation was complimented by the views of the shipping industry too. This is seen through visible positive attitude towards safety: promoting a safety culture, enough funding towards safety activities, and management commitment [17]. According to all participants, the management of the shipping companies have demonstrated their commitment clearly in comparison with before the implementation of the ISM Code.

The management provides resources and funds for safety investments and safety trainings targeted at the crew. Every participant stressed that the top management have a lot more interest regarding safety. The interviews revealed no opposite reflections. No participant said that the management are purely indifferent or negligent. In the light of the results of this research, it seems that the top management are responsible and aware of safety.

Employee participation was apparent. Each participant gave a positive and consistent opinion regarding the employee participation in meetings and on-board activities. For example, seafarers are active and initiate suggestions about safety, they ask questions independently and seek advice from their superiors when necessary. They are encouraged to discuss safety issues and highlight problems and faults. Both seafarers and resource persons mentioned the importance of their training courses and each shared a positive opinion about how they actively participate in the safety trainings. They emulate near misses when manage- 
ment communicates relevant reports as case studies, and they attend trainings to prevent incidents from reoccurring.

Participants indicated that the implementation of the ISM Code is beneficial and essential. The individual interviews were quite consensual about the issue. No respondent presented any arguments against the usefulness of safety management. Seafarers shared a common opinion that the responsibility the ISM Code imposes onto the company and management is one of the most significant benefits of the ISM Code about taking care of safety. One of the advantages of the safety management system is that it clarifies the roles and responsibilities on board, as they are defined in the system. To them, the clarified roles and responsibilities provide several concrete benefits: they know who to contact and they can rely on the fact that the company must take a stand on a matter; clarified roles and responsibilities facilitate better communication between the ships and the office.

The seafarer's views were backed up by the resource persons. They highlighted that the safety management systems have unified the procedures on board, which has made the maritime personnel's job much easier. To them, this makes it easier to orientate new employees and to transfer personnel from one ship to another as well. They all shared the opinion that it is beneficial that the procedures related to safety are documented and the needed instructions are easily found. The users can rely on the fact that they are following correct, current and accepted guidelines provided by the documentation of the SMS. Participants reported that, they do not have to learn new things by trial and error. Moreover, most participants thought that the harmonised procedures and system documentation maintain the continuity of good practices on board, as the crew members are changing.

\section{LIMITATIONS OF THE STUDY}

The sample was small, and the results cannot be generalised. However, they could be used as indicators towards successful improvement of safety culture in the maritime industry.

Also, several attempts to conduct interviews with maritime industry Chief Executive Officers were unsuccessful; therefore, the team chose to interview resource persons. Chief Executive Officers may provide more in-depth views regarding the implementation of the ISM Code but the views of the resource persons are in any case compatible.

Some future research directions are desired, e.g., conducting the same research in other countries or regions.

\section{CONCLUSIONS}

Through literature review, six factors were identified and proposed as critical factors to be tested empirically. Through analyses and discussions of empirical findings, it has been supported that the proposed factors are verified by interview informants. It is apparent from this research that the successful implementation of the ISM Code depends on several key factors such as maritime safety awareness which should be resulted from the safety culture promulgated and fostered across all the relevant stakeholders and the shipping industry. The role of senior management both in maritime administration and shipping companies, is especially important to nurture the safety culture, as well as providing support such as training for employees in implementing the Code. Other factors which are essential for the Code implementation are also confirmed such as training and development for shipping personnel, quality management principles applied to safety management systems, rationalisation of documentation, and employee involvement and empowerment.

This study found that all participants are well informed about the ISM Code as it is encountered in their everyday life. They also believed that with the Code in place, their SMS has prevented accidents from occurring. Participants' attitudes towards safety have also improved both on management level and among seafarers during the past 15 years. This positive change in attitude can be seen in the management's support, safety equipment and moral, for safety and security issues. Seafarers reveal their changed attitudes by following and complying with safety measures, rules and regulation most of the time. Both the management and the personnel feel that safety is a part of their day-to-day work. And this is all due to the implementation of the ISM Code.

The implementation of the ISM Code is perceived mainly as positive. The ISM Code has ensured; better organization of operations, clarified roles and responsibilities of maritime personnel, and the systematic approach to safety management which lead to helping personnel to assimilate instructions and safe working methods. Seafarers also considered that the introduction of the ISM Code forced companies to actively engage and take responsibilities concerning safety. Therefore, the ISM Code has fulfilled its original purpose.

\section{Conflict of interest: None declared}

\section{REFERENCES}

1. International Maritime Organization. ISM Code, International Safety Management code and guidelines on implementation of the ISM code. IMO Publishing, London 2010.

2. RodriguezAJ. Campbell Hubbard M. International Safety Management(ISM) Code: ANew Level of Uniformity. 73, Tulane Law Review 1999: 1585-1618.

3. Department of Transport. The Merchant Shipping Act 1894, mv Herald of Free Enterprise. Report court no. 8074, Formal Investigation, Department of Transport, HMSO, London 1987.

4. Robinson A. The Scandinavian Star Incident: A Case Study. Fire Engineers Journal. 1999; 59: 36-38. 
5. Bhattacharya S. Impact of the ISM Code on the Management of Occupational Health and Safety in the Maritime Industry. (Doctoral dissertation). Cardiff University 2009.

6. Roberts SE. Hazardous occupations in Great Britain. Lancet. 2002; 360(9332): 543-544, doi: 10.1016/S0140-6736(02)09708-8, indexed in Pubmed: 12241660.

7. Home WE. Mortality of British merchant seamen. Lancet. 1934; 223(5777): 1081-1083, doi: 10.1016/s0140-6736(00)94094-7.

8. Karakasnaki M, Vlachopoulos P, Pantouvakis A, et al. ISM Code implementation: an investigation of safety issues in the shipping industry. WMU Journal of Maritime Affairs. 2018; 17(3): 461-474, doi: 10.1007/s13437-018-0153-4.

9. Marlow A Motivation and Personality. Harper and Row, New York 1970.

10. Alderfer $\mathrm{C}$. An empirical test of a new theory of human needs. Organizational Behavior and Human Performance. 1969; 4(2): 142-175, doi: 10.1016/0030-5073(69)90004-x.
11. Conger J, Kanungo R. The empowerment process: integrating theory and practice. Academy of Management Review. 1988; 13(3): 471, doi: $10.2307 / 258093$.

12. Siegall M, Gardner S. Contextual factors of psychological empowerment. Personnel Review. 2000; 29(6): 703-722, doi: 10.1108/00483480010296474.

13. Kanter R. Men and women of the corporation. Basic Books, New York, 1977.

14. Kanter RM. Men and women of the corporation. 2nd ed. Basic Books, New York 1993.

15. Degner LF. Knowledge translation in palliative care: can theory help? Can J Nurs Res. 2005; 37(2): 105-113, indexed in Pubmed: 16092783.

16. Patton MQ. Qualitative research and evaluation methods. 3 ed. Thousand Oaks, Sage Publications 2002.

17. Wiegmann DA, Zhang $H$, von Thaden $T$, Sharma G, Mitchell A. A synthesis of safety culture and safety climate research. University of Illinois, Aviation Research Lab, Savoy 2002. 